\title{
The Economics of Free Internet Access
}

\author{
Marco Haan \\ University of Groningen*
}

October 14,2000

\begin{abstract}
In an increasing number of European countries, internet service providers offer free internet access. Telephone companies are willing to pay these providers based on the amount of traffic they generate. In this paper, we explain these phenomena. We argue that, by offering a contract that pays the provider a certain lump-sum conditional on it providing free internet access, the telephone company solves a double marginalization problem. We analyze this in a simple model in which only the internet access market is studied, and in a richer model, where the regular telephone market is also taken into account.
\end{abstract}

JEL Classification Codes: L12, L22, L42.

Keywords: Internet Access, Vertical Market Structure.

*Department of Economics, PO Box 800, 9700 AV Groningen, The Netherlands. email: m.a.haan@eco.rug.nl. The most recent version of this paper can be found at http: //www.eco.rug.nl/ haanma. Financial support from the Netherlands Organization for Scientific Research (NWO) is gratefully acknowledged. The author thanks Christa Bouwman, Thijs Knaap, Ruud Koning, Peter Kooreman, Yohanes Riyanto, Lambert Schoonbeek, Ton Steerneman and Bjørn Volkerink for useful discussion and comments. 


\section{Introduction}

In an increasing number of European countries, internet service providers (ISPs) offer free unlimited internet access. With such a service, consumers can use the internet without paying their service provider anything. In the UK, free internet access was introduced by electronics retailer Dixons in the fall of 1998. Its service, Freeserve, attracted 1.3 million subscribers in seven months (The Economist, 1999a). Less than a year after its introduction, it has spawned nearly 100 imitators in Britain alone (The Economist, 1999b). In the Netherlands, some small providers introduced free internet access on a limited scale in the spring of 1999. World Online, the largest service provider, followed by lowering prices to zero in August of the same year (see Volkskrant, 1999). Other large providers followed within weeks (see e.g. Telegraaf 1999). Since then, dozens of new free access providers have been introduced. Also in France, Germany and Belgium, free internet access has been either introduced or announced. (The Economist, 1999b, van Jole 1999).

For an economist, this is a surprising development. The assumption that firms maximize profits seems hard to square with the observation that they give away their product for free. One explanation is that these ISPs now make their money from advertisements on their website. Subscribers to a certain provider, the argument goes, often use the website of that provider as their starting point for exploring the World Wide Web. Therefore, advertisements on these websites will attract a lot of viewers, and thus generate a lot of revenue for the access provider. Yet, it seems unlikely that this increase in advertising can cover the decrease in revenue from access charges. Before free internet access was provided, consumers still had to pay substantial amounts for that service. Moreover, the most heavy users of the internet, which are the most attractive for advertisers, are also the users most likely to change the settings of their web browser and bypass the advertisements of their access provider. Whereas the possibility of advertising may explain that prices for internet access fall, there seems little reason to expect them to drop to zero. Therefore, there must be a different explanation for this phenomenon.

What is also observed in countries where free internet access is provided, is that telephone companies pay a certain, often undisclosed amount of money to free internet access providers, based on the amount of revenue they generate for the telephone company (The Economist, 1999a, Volkskrant 1999). ${ }^{1}$ Again, this seems hard to explain. By doing so,

\footnotetext{
${ }^{1}$ In the UK, the telecom regulator even requires that British Telecom "share[s] the money it collects for
} 
the price of a telephone call for the end user does not change, and therefore demand will be unaffected. But then this practice suggests that the telephone company is willing to transfer part of its profit to the access provider. That also seems a strange thing to do for a profit maximizing firm.

In the Us, an increasing number of firms, like AltaVista or Net Zero, also claim to provide free internet access. Yet, so far, all these services come with a catch; they require that users permanently have a window open on their desktop in which the provider shows advertisements (See e.g. Yurko, 1999; "The trade-off for the free internet access is an omnipresent banner flashing advertisements that you can't turn off"). Therefore, these services cannot be compared to those offered in Europe. This raises another question: given the substantial lead of the Us in virtually all internet-related areas, why is truly free internet access only offered in Europe?

In this paper, we explain these observations. In a nutshell, the argument is as follows. Suppose we are in a world without free internet access. The end price an internet user pays for internet access equals the sum of the price of a telephone call and the price that has to be paid to the internet service provider. When both the telephone company and the service provider are monopolists, they both set a price that does not take the effect of the profit of the other monopolist into account. Thus, the end price is the sum of two monopoly prices. This implies that the loss in consumer surplus is larger than in the case of a simple monopoly, since there are now two monopolists who try to extract surplus from consumers. Both monopolists set prices that are too high, in the sense that joint profits are not maximized. This effect is closely related to the double marginalization problem, studied in the theory of vertical market structure. ${ }^{2}$.

There are several ways in which the two monopolists can solve this problem, internalize the negative effects of their pricing decisions, and maximize joint profits. For our set-up, we will argue that the most obvious solution is the following. The telephone company can offer a contract to the internet service provider, promising to pay him a certain lump sum conditional on the provider setting a certain price. We derive conditions under which it is optimal to offer a contract that induces the ISP to set prices equal to zero, i.e. to provide free internet access.

special "local-rate" numbers of the sort issued by ISPs with the firm that takes the call" (The Economist, 1999a). In other countries, however, such a requirement does not exist, and telephone companies volunteer to such a sharing deal.

${ }^{2}$ Introduced by Spengler (1950). See also Tirole (1988), chapter 4. 
The remainder of this paper is structured as follows. In section 2 we study the simplest possible model, in which only the market for internet access is considered. We derive the solution to a benchmark case, in which there is a positive price for internet access. Then we show that the telephone monopolist has an incentive to offer a contract to the service monopolist, inducing the latter to offer free internet access. Also, we show that this contract is indeed profit-maximizing for the telephone monopolist. We explain why free internet access was not offered immediately when the market for internet access emerged, and study the case of an access oligopoly. Section 3 studies a richer model in which two markets are considered; one for internet access and one for regular telephony. We show that in such a framework, free internet access may also be optimal for the telephone monopoly. Yet, the telephone company may now prefer to offer a contract that specifies a strictly positive

price for internet access. This richer set-up also allows us to study the welfare effects of free internet access. We show that free internet access makes the telephone monopoly and internet users better off. The ISP and regular telephone users, however, are usually worse off. In this framework, we show that free internet access may also be offered when the telephone monopoly fully owns the internet access monopoly. Finally, section 4 concludes.

\section{Free internet access in a simple model}

\subsection{Introduction}

In this section, we illustrate our main argument with a simple model, where only the market for internet access is considered. The benchmark model, in which prices are decided unilaterally, is introduced in section 2.2. In section 2.3, we show that the telephone company can always improve upon the outcome of the benchmark model, by offering a contract to the service provider, which obliges the telephone company to pay a certain specified amount $L$, when the access provider drops his price to zero. In section 2.4, we extend the contract space, and consider the case in which the telephone company can write a contract conditional on any access fee the service provider may charge. The optimal contract for the telephone company then specifies an access fee equal to zero. Section 2.5 gives a simple explanation as to why it took some time before free internet access was offered. We show that, with fixed costs of contracting, the market first has to reach a critical size before offering a contract is profitable. Finally, section 2.6 studies the case in which the market for internet service providers is an oligopoly rather than a monopoly. We show that, as 
that market is less concentrated, the size of the market has to be higher before free internet access will be offered.

\subsection{The benchmark model}

Assume we have two firms, one providing telephony, the other providing internet access. Both firms are a monopolist in their market. Demand for internet services is given by

$$
q=\gamma-p, \text { for } p \geq 0
$$

Here, $q$ is total demand per time unit. Thus, $q$ gives, for example, the number of minutes of internet access demanded per week. The full price the consumer has to pay for one minute of internet access is given by $p$, whereas $\gamma$ is some exogenous parameter. Note that, in order to have internet access, a consumer has to pay, first, the telephone company for the telephone connection and, second, the service provider for internet access. Therefore, the full price $p$ is given by $p=p_{T}+p_{A}$, with $p_{T}$ the price charged by the telephone company, and $p_{A}$ the price charged by the service provider. For simplicity, we assume that marginal cost of both the telephone company and service provider are equal to zero. We restrict both prices to be non-negative.

Assume that the telephone company $T$ can commit to some price $p_{T}$ before the service provider sets its price $p_{A}$. There can be several reasons for this. Prices of the telephone company also hold for regular telephony, and may therefore be less flexible to change. The number of subscribers for the service provider is lower, hence it is easier and cheaper to inform them of any change in prices. Alternatively, we may have that firm $T$ already advertises in advance the price it is going to charge in the subsequent period. Anyhow, this assumption is innocuous; we show later that our main results also hold when we assume that both monopolists set their prices simultaneously.

Profits of firm $T$, the telephone company, are given by $\pi_{T}=p_{T}\left(\gamma-p_{T}-p_{A}\right)$, whereas those of firm $A$, the access provider, can be written $\pi_{A}=p_{A}\left(\gamma-p_{T}-p_{A}\right)$. Maximizing the latter yields

$$
p_{A}=\frac{\gamma-p_{T}}{2}
$$

Plugging this back into $\pi_{T}$ and maximizing with respect to $p_{T}$ yields

$$
p_{T}=\frac{1}{2} \gamma ; \quad p_{A}=\frac{1}{4} \gamma
$$


Equilibrium profits thus equal

$$
\pi_{T}=\frac{1}{8} \gamma^{2} ; \quad \pi_{A}=\frac{1}{16} \gamma^{2} .
$$

Note that these prices imply that the total price of internet access, $p=\frac{3}{4} \gamma$, exceeds the price that would be set by a monopolist controlling both telephony and internet access. It is easy to see that such a monopolist would set $p=\frac{1}{2} \gamma$, yielding profits $\pi=\frac{1}{4} \gamma^{2}$, which exceeds total profits of firms $A$ and $T$ in the scenario described above. This suggests that there is some scope for side-payments. In fact, the situation is virtually identical to one in which a monopolist manufacturer supplies a crucial input to a monopolist retailer. This can be seen as follows. Suppose that, in such a set-up, demand for the end product is given by (1). The manufacturer supplies its product to the retailer and charges price $p_{T}$. Marginal costs for the retailer thus equal $p_{T}$, and it sets retail price given by (2). Given that decision, the manufacturer sets $p_{T}=\frac{1}{2} \gamma$. Also in this set-up, joint profits of the two monopolists are not maximized, since both set a monopoly price. Spengler (1950) coined this the double marginalization problem. The retail price is higher in a decentralized structure than in an integrated one, because of two successive mark-ups or marginalizations (Tirole 1988, p. 174). In this set-up, there are two obvious ways to solve the double marginalization problem. First, the two firms can merge, and internalize the problem. Second, the monopolist manufacturer can charge the retailer a franchise fee equal to the total (integrated) monopoly profits, and supply the good at marginal costs. The retailer will then set the integrated monopoly price, earn integrated monopoly profits, but has to pass them on to the manufacturer as a franchise fee.

Both solutions, however, are not feasible in the set-up described in this paper. A merger is not likely to be cleared by antitrust authorities, especially not in the case where more internet service providers exist, which all have to be included in such a merger. A franchise fee can only be used when the upstream monopolist is able to effectively shut out the downstream monopolist from the use of its product when the latter refuses to pay the franchise fee. In a standard vertical setting this is feasible, since the monopolist manufacturer can simply refuse to sell the product to the retailer. Yet, in the context of internet access provision, this will be hard. Having a universal service obligation, the telephone company is not able to stop the access provider from using its net.

In the next subsection we therefore propose a different solution. We consider the case in which the telephone company offers a take-it-or-leave-it contract to the service provider, 
committing to paying it some lump-sum $L$ if and only if the latter charges price zero.

\subsection{Free internet access}

Given the model described in the previous subsection, now consider the case in which firm $T$, the telephone company, can offer a take-it-or-leave-it contract to firm $A$, the access provider. In this contract, firm $T$ offers to pay some lump-sum $L$ to firm $A$, conditional on $A$ setting $p_{A}=0$. In other words, the telephone company offers a lump-sum to the access provider, if the latter provides free internet access.

Again, we assume that $T$ can credibly commit to some price $p_{T}$ before offering the contract. First $T$ sets some price $p_{T}$. Then, it offers $A$ a take-it-or-leave-it contract. Given the terms of that contract, $A$ decides whether to accept or reject it. If it accepts, it sets $p_{A}=0$ and receives a lump-sum $L$, as specified in the contract. If it rejects, it sets $p_{A}$ as to maximize its profits, and does not receive any transfer from $T$.

Obviously, $T$ will design the contract in such a way that $A$ will just accept its terms. When rejecting the contract, $A$ maximizes profits by setting $p_{A}$ following (2). Hence, $T$ needs to set

$$
L=\left(\frac{\gamma-p_{T}}{2}\right)^{2},
$$

which will just be accepted by firm $A$. Total profits from offering this contract equal

$$
\pi_{T}^{C}=p_{T}\left(\gamma-p_{T}\right)-\left(\frac{\gamma-p_{T}}{2}\right)^{2} .
$$

Maximizing with respect to $p_{T}$ yields

$$
p_{T}=\frac{3}{5} \gamma .
$$

Using (5) and (6), total profits for firm $A$ now equal

$$
\pi_{A}^{C}=\frac{1}{25} \gamma^{2},
$$

whereas profits of firm $T$ are

$$
\pi_{T}^{C}=\frac{1}{5} \gamma^{2} .
$$

There are a few things to note. First, comparing these expressions with (4), total profits of the two firms have indeed increased. Second, and more importantly, the profits of firm $T$ have increased, whereas those of firm $A$ have decreased. Thus, even though $T$ offers firm $A$ a contract which $A$ is free to reject, this situation still makes $A$ worse off than it 
was in the case in which such a contract was not offered. The reason for this is that $T$ now sets its price $p_{T}$ by also taking its effect on the contract into account. By increasing $p_{T}$, direct monopoly profits decrease, but the lump-sum $T$ has to offer to $A$ also does. Therefore, the price $T$ sets is higher than the monopoly price $p_{T}=\frac{1}{2} \gamma$ it would set when it were an integrated monopolist controlling both telephony and internet access. The third thing to note is that, in this simple model, internet users are always better off. Without the contract, the full price they had to pay for internet access equals $p=\frac{3}{4} \gamma$. With the contract, they only pay $p=p_{T}=\frac{3}{5} \gamma$.

So far, we assumed that firm $T$ can commit in advance as to which price $p_{T}$ it will set. Now suppose the telephone cannot commit in advance to a price $p_{T}$. We first study the effect of that decision in the benchmark model. When both set their prices simultaneously, we have reaction functions $p_{T}=\left(\gamma-p_{A}\right) / 2$ and $p_{A}=\left(\gamma-p_{T}\right) / 2$, and equilibrium prices $p_{A}=p_{T}=\frac{1}{3} \gamma$, yielding profits

$$
\pi_{A}=\pi_{T}=\frac{1}{9} \gamma^{2}
$$

In this set-up, suppose firm $T$ offers a contract. Since it cannot commit to a price in advance, the access provider knows that when it rejects the contract, it can obtain the profits given by (10). Therefore, firm $T$ needs to set $L=\frac{1}{9} \gamma^{2}$, and its profits are given by $\pi_{T}=p_{T}\left(\gamma-p_{T}\right)-\frac{1}{9} \gamma^{2}$, which are maximized by setting $p_{T}=\frac{1}{2} \gamma$. Profits now equal $\pi_{T}=\frac{5}{36} \gamma^{2}$ for firm $T$, and $\pi_{A}=\frac{1}{9} \gamma^{2}$ for firm $A$. Again, profits of firm $T$ increase compared to the benchmark case, whereas, trivially, profits of firm $A$ do not change. Consumers are better off, since full access prices fall from $\frac{2}{3} \gamma$ to $\frac{1}{2} \gamma$. Again, in equilibrium, firm $T$ will offer a contract that implies free internet access. For the remainder of this paper, we assume that firm $T$ can commit to a price in advance.

We assumed in this subsection that the contract offered by firm $T$ specifies some lumpsum payment. In practice we do not see such lump-sums being paid. Rather, the telephone company pays some fixed amount $t$ to the service provider for each minute of telephone traffic the latter generates. In this model, it is trivial to see that this boils down to the exact same thing. Rather than paying the lump-sum amount given by (5), we simply have, using (7),

$$
t=\frac{L}{q}=\frac{\left(\frac{\gamma-p_{T}}{2}\right)^{2}}{\gamma-p_{T}}=\frac{\gamma-p_{T}}{4}=\frac{\gamma}{10} .
$$

In the real world, offering such a contract is probably a better idea, since a lump-sum payment would give the service provider an incentive to shirk on the quality it provides, 
which lowers the demand for internet access, an effect that is not captured in our simple demand function (1). Nevertheless, given that in our model the two types of contract are identical, we assume for simplicity a lump-sum payment in the remainder of this paper.

\subsection{Free access as the optimal contract}

We showed that the telephone company can improve upon the benchmark case by offering a contract to the access provider that gives the latter a fixed lump-sum conditional on it providing free internet access. In this section, we show that this contract is optimal from the point of view of the telephone company. We thus enlarge the set of possible contracts, by allowing firm $T$ to offer any contract in which it pays $L$ to firm $A$ if and only if the latter sets some price $p_{A}^{C} \geq 0$.

Given $p_{T}$, profits to firm $A$ when rejecting the contract again are $\left(\frac{\gamma-p_{T}}{2}\right)^{2}$. Yet, profits when accepting the contract now equal $\pi_{A}^{C}=p_{A}^{C}\left(\gamma-p_{A}^{C}-p_{T}\right)+L$. Thus, for firm $A$ to accept the contract, we need

$$
L \geq\left(\frac{\gamma-p_{T}}{2}\right)^{2}-p_{A}^{C}\left(\gamma-p_{A}^{C}-p_{T}\right)
$$

Total profits of firm $T$ equal $\pi_{T}^{C}=p_{T}\left(\gamma-p_{A}^{C}-p_{T}\right)-L$. Using (12), this implies

$$
\pi_{T}^{C}=\left(p_{T}+p_{A}^{C}\right)\left(\gamma-p_{A}^{C}-p_{T}\right)-\left(\frac{\gamma-p_{T}}{2}\right)^{2} .
$$

The telephone company maximizes $\pi_{T}^{C}$ subject to the non-negativity constraints on prices. The Lagrangean equals

$$
\mathcal{L}=\left(p_{T}+p_{A}^{C}\right)\left(\gamma-p_{A}^{C}-p_{T}\right)-\left(\frac{\gamma-p_{T}}{2}\right)^{2}+\lambda p_{T}+\mu p_{A}^{C},
$$

with $\lambda, \mu \geq 0$ the respective Lagrange-multipliers. Taking first-order conditions

$$
\begin{aligned}
\frac{\partial \mathcal{L}}{\partial p_{A}^{C}} & =\gamma-2\left(p_{A}^{C}+p_{T}\right)+\mu=0 \\
\frac{\partial \mathcal{L}}{\partial p_{T}} & =\frac{3}{2} \gamma-2 p_{A}^{C}-\frac{5}{2} p_{T}+\lambda=0
\end{aligned}
$$

The Kuhn-Tucker conditions are given by

$$
\begin{aligned}
\lambda p_{T} & =0 \\
\mu p_{A}^{C} & =0 .
\end{aligned}
$$


Solving for $p_{T}$ and $p_{A}^{C}$ yields

$$
\begin{aligned}
& p_{T}=\gamma-2 \mu+2 \lambda, \\
& p_{A}^{C}=\frac{5}{2} \mu-\frac{1}{2} \gamma-2 \lambda .
\end{aligned}
$$

Suppose $p_{A}^{C}>0$. Then, from (18), we would have $\mu=0$. Yet, plugging that into (20) yields $p_{A}^{C}=-\frac{1}{2} \gamma-2 \lambda<0$, which is a contradiction. Thus, the telephone company will optimally offer a contract with $p_{A}^{C}=0$, i.e. a contract that implies free internet access. Setting $p_{A}^{C}=0$ in (20) yields $\mu=\frac{1}{5} \gamma-\frac{4}{5} \lambda$. Plugging this into (19) and setting ${ }^{3} \lambda=0$, yields

$$
p_{T}=\frac{3}{5} \gamma
$$

Profits of firm $T$ then equal

$$
\pi_{T}^{C}=\gamma^{2} / 5
$$

Note that the free internet access result does not hinge on the fact that we have assumed zero marginal cost for both firms. Our equilibrium implies that the price for internet access per se really equals zero, and is not simply equal to marginal cost, which happen to be zero as well. It is straightforward to show that, for any fixed marginal cost $c<\frac{1}{2} \gamma$ for the telephone company, the optimal contract still implies $p_{A}^{C}=0$, i.e. free internet access.

\subsection{From paid access to free access}

In the previous subsections we showed why free internet access may be offered. Yet, our explanation seems to be too successful, in the sense that we did not explain why free internet was not offered from the very instant the market emerged. In this subsection, we show how a slight adaptation of our model can allow for this.

Suppose that for firm $T$, there are transaction costs involved in setting up, formulating and policing a contract. Assume these costs equal F. Also, assume that the market for internet access grows through time. This can be modelled as an exogenous increase in the parameter $\gamma$. As $\gamma$ increases, the demand curve (1) shifts outwards. Note that the increase in profits to the telephone company from offering a contract equals $\Delta \pi_{T}=\frac{1}{5} \gamma^{2}-\frac{1}{8} \gamma^{2}=\frac{3}{40} \gamma^{2}$. Hence, it will find it profitable to offer a contract if and only if $\gamma \geq \frac{2}{3} \sqrt{30 F}$. Therefore, free internet access will only be offered if that critical size of the market is reached.

\footnotetext{
${ }^{3}$ Any $\lambda>0$ implies, from (17), $p_{T}=0$, which, using (19), would yield a negative value for $\lambda$, which is a contradiction.
} 


\subsection{The case of an access oligopoly}

Now assume the market for internet access is an oligopoly, where $N$ internet service providers are active. Timing is as follows. First, the telephone monopoly sets $p_{T}$. Then, the access firms compete in a Cournot fashion. Admittedly, it may be more natural for this market to assume price competition. Yet, in this simple framework, that would yields zero profits for any $N \geq 2$. One way to justify the assumption of Cournot competition, is by assuming that firms first choose their capacity and then compete in prices. As Kreps and Scheinkman (1983) have shown, this game yields the same outcome as one in which firms compete in quantities. The implicit demand function for the IsPs can be written

$$
p_{A}=\gamma-p_{T}-\sum_{j=1}^{N} q_{A_{j}},
$$

with $q_{A_{j}}$ the quantity set by service provider $A_{j}, j=1, \ldots, N$. Firm $A_{i}$ 's profits then equal $\pi_{A_{i}}=q_{A_{i}}\left(\gamma-p_{T}-q_{A_{i}}-\sum_{j \neq i} q_{A_{j}}\right)$. Maximizing with respect to $q_{A_{i}}$ yields $q_{A_{i}}=$ $\frac{1}{2}\left(\gamma-p_{T}-\sum_{j \neq i} q_{A_{j}}\right)$. For an equilibrium, we need symmetry, i.e. $q_{A_{i}}=q_{A_{j}} \forall i, j \in$ $\{1, \ldots, N\}$. This yields $q_{A_{i}}=\frac{\gamma-p_{T}}{N+1}$, yielding a price for internet access $p_{A}=\frac{1}{N+1}\left(\gamma-p_{T}\right)$. Given these reactions, the telephone monopoly's profits are given by

$$
\begin{aligned}
\pi_{T} & =p_{T}\left(\gamma-p_{T}-\frac{1}{N+1}\left(\gamma-p_{T}\right)\right) \\
& =p_{T}\left(\frac{N}{N+1}\right)\left(\gamma-p_{T}\right)
\end{aligned}
$$

which is maximized by setting $p_{T}=\frac{1}{2} \gamma$, yielding profits $\pi_{T}=\frac{1}{4} \gamma^{2} N /(N+1)$.

Now suppose the telephone company considers offering a contract. Note that the contract now has to be in quantities, rather than prices. ${ }^{4}$ To induce $p_{A}=0$, using (23), it has to offer each firm $\left(\gamma-p_{T}\right) / N$. Suppose firm $A_{i}$ unilaterally defects and does not accept the term of the contract. Given that all other firms do accept, its profits can then be written $\pi_{A_{i}}^{d}=q_{A_{i}}\left(\gamma-p_{T}-\frac{N-1}{N}\left(\gamma-p_{T}\right)-q_{A_{i}}\right)=q_{A_{i}}\left(\frac{1}{N}\left(\gamma-p_{T}\right)-q_{A_{i}}\right)$, which is maximized by

\footnotetext{
${ }^{4}$ If the contract were in prices rather than quantities, the telephone company would simply be able to set a lump-sum transfer $L=0$ for any number of access firms $N \geq 2$. Any firm $A_{i}$ would accept this contract. By defecting, it cannot make any profits, since it can only charge a price $p_{A_{i}}>0$. But by doing so, demand for its services would be zero. Therefore, we do not consider this to be an interesting case. To circumvent this possibility, we could assume that the products of the access firms are differentiated, for example in the way modelled by Singh and Vives (1984). Yet, this would complicate our model, without yielding any additional insights compared to the case in which we assume that firm $T$ offers contracts in terms of quantities rather than prices, as we do in the main text.
} 
setting $q_{A_{i}}=\frac{1}{2 N}\left(\gamma-p_{T}\right)$, yielding profits

$$
\pi_{A_{i}}^{d}=\frac{\left(\gamma-p_{T}\right)^{2}}{4 N^{2}}
$$

Hence, in order for every access firm to accept the terms of the contract, firm $T$ has to offer each a lump-sum $L_{A_{i}}$ equal to $\pi_{A_{i}}^{d}$, as defined in (25). Total costs of doing so equal

$$
L=\sum_{i=1}^{N} L_{A_{i}}=\frac{\left(\gamma-p_{T}\right)^{2}}{4 N}
$$

Total profits of firm $T$ are $\pi_{T}^{C}=p_{T}\left(\gamma-p_{T}\right)-\frac{\left(\gamma-p_{T}\right)^{2}}{4 N}$. Maximizing with respect to $p_{T}$ yields

$$
p_{T}=\frac{2 N+1}{4 N+1} \gamma
$$

Note that total lump-sum transfers, plugging (27) into (26), equal

$$
L=\frac{\gamma^{2} N}{(4 N+1)^{2}}
$$

which is decreasing in $N$. Hence, the larger the number of access oligopolists, the smaller the total amount of lump-sum transfers the telephone company has to make. Total profits on the access market decrease as $N$, the amount of firms active, increases. Thus, as $N$ increases, firm $T$ can offer a lower amount of money in order to induce all competitors to accept the contract. This also suggests that firm $T$ has an interest in stimulating competition in the market for internet access, even when it is already offering contracts to incumbents to provide free internet access.

Total profits of firm $T$ now equal $\pi_{T}^{C}=\frac{\gamma^{2} N}{4 N+1}$. The increase in profits for firm $T$ is

$$
\Delta \pi_{T}=\frac{\gamma^{2} N}{4 N+1}-\frac{\gamma^{2} N}{4(N+1)}=\frac{3 \gamma^{2} N}{4(4 N+1)(N+1)}
$$

When contracting with each individual firm comes at a cost $F$, and total contracting costs thus equal $N F$, we need $\gamma>2 \sqrt{F(4 N+1)(N+1) / 3}$ for free internet access to occur. The RHS of this inequality is increasing in $N$. Hence, the market has to be bigger for free internet access to emerge as the number of access competitors increases.

Interestingly, this result does not hinge on the constant returns to scale in contracting we assume. As the other extreme, suppose the telephone company has to pay fixed contracting costs $F$ regardless of $N$. In that case, we need $\gamma>2 \sqrt{F(4 N+1)(N+1) / 3 N}$, which is also increasing in $N$. 


\section{Free internet access with two markets}

\subsection{Introduction}

In the previous section, we illustrated the basic mechanism as to why internet service providers may be willing to offer free internet access, and telephone companies are willing to pay ISPs based on the amount of traffic they generate. So far, however, we have only considered the market for internet access. Obviously, the telephone company is also active on the market for regular telephony. To fully appreciate the effects of free internet access, we also have to take the effect on that market into account. In this section, we analyze a model which allows us to do just that.

In section 3.2, we discuss the benchmark model, and solve it in a world without contracts. In section 3.3, we introduce the possibility of a contract. Section 3.4 studies the welfare effects. Finally, section 3.5 shows that when firm $T$ fully owns firm $A$, free internet access can also maximize its profits.

\subsection{The benchmark model}

Again, we assume that demand for internet services is given by

$$
q=\gamma-p_{A}-p_{T}
$$

and denote the full price of internet access as $p=p_{A}+p_{T}$. When consumers want to make a phone call, they only need to use the services of firm $T$. Hence, demand for regular telephony only depends on the price for the telephone connection, $p_{T}$. In particular, we assume

$$
Q=1-\alpha p_{T},
$$

with $Q$ the demand for regular telephony, and $\alpha$ some parameter with $\alpha>0$. We assume that firm $T$ cannot discriminate between consumers who use their phone to make a simple voice call, and those that use the phone to connect to an internet access provider. Note that, by choosing units conveniently, (30) and (31) cover all possible linear demand configurations.

Again, the profit-maximizing price of firm $A$, given that firm $T$ sets $p_{T}$, is given by (2). Total profits of the telephone company therefore equal ${ }^{5} \pi_{T}=p_{T}\left(1-\alpha p_{T}\right)+p_{T}\left(\frac{\gamma-p_{T}}{2}\right)$,

\footnotetext{
${ }^{5}$ Or, more precisely, $\pi_{T}=\max \left\{p_{T}\left(1-\alpha p_{T}\right), 0\right\}+\max \left\{p_{T}\left(\frac{\gamma-p_{T}}{2}\right)\right\}$.
} 
where the first term denotes its profit from the telephone market, and the second term that from the internet market. Maximizing profits yields

$$
p_{T}=\frac{2+\gamma}{2+4 \alpha}
$$

For both markets to exist, we need that $\alpha$ and $\gamma$ are such that demand on both the telephony and the internet market is non-negative. Hence, using (30) and (31), we need ${ }^{6}$

$$
\frac{2}{1+4 \alpha}<\gamma<\frac{2+2 \alpha}{\alpha}
$$

For lower $\gamma$, firm $T$ simply sets the price that maximizes profits on the market for regular telephony, i.e. $p_{T}=\frac{1}{2 \alpha}$, and $q=0$, whereas for higher $\gamma$, firm $T$ sets the price that maximizes profits on the internet market; $p_{T}=\gamma / 2$, and $Q=0$.

Total profits of both firms for $\alpha$ and $\gamma$ in the interval given by (33) equal

$$
\pi_{T}=\frac{1}{8} \frac{(2+\gamma)^{2}}{1+2 \alpha} ; \quad \pi_{A}=\frac{1}{16}\left(\frac{\gamma+4 \gamma \alpha-2}{1+2 \alpha}\right)^{2} .
$$

Summarizing,

Theorem 1 When the telephone market is also taken into account, and the telephone company cannot offer a contract to the internet service provider, equilibrium prices are given by

$$
\left(p_{T}, p_{A}, p\right)=\left\{\begin{array}{clcc}
\left(\frac{1}{2 \alpha}, \infty, \infty\right) & \text { if } & \gamma<\frac{2}{1+4 \alpha}, \\
\left(\frac{2+\gamma}{2+4 \alpha}, \frac{\gamma+4 \alpha \gamma-2}{4+8 \alpha}, \frac{3 \gamma+4 \alpha \gamma+2}{4+8 \alpha}\right) & \text { if } & \frac{2}{1+4 \alpha}<\gamma<\frac{2+2 \alpha}{\alpha} \\
\left(\frac{1}{2} \gamma, \frac{1}{4} \gamma, \frac{3}{4} \gamma\right) & \text { if } & \gamma>\frac{2+2 \alpha}{\alpha}
\end{array}\right.
$$

\subsection{Offering a contract}

Suppose now that in this world, firm $T$ can offer a take-it-or-leave-it contract to firm $A$, promising to pay it a lump-sum $L$ if and only if it sets $p_{A}^{C}$. Firm $T$ can follow several possible strategies. First, it can choose to offer a contract, and serve both the telephone and the internet market. Second, it can choose to bypass the internet market by setting a price such that demand on the internet market is zero. Third, it can choose to offer a

\footnotetext{
${ }^{6}$ Note that, for $(33)$ to be feasible, we need $\frac{2}{1+4 \alpha}<\frac{2+2 \alpha}{\alpha}$. This implies $2 \alpha<(2+2 \alpha)(1+4 \alpha)$, thus $8 \alpha^{2}+8 \alpha+2>0$, which is satisfied for any $\alpha>0$.
} 
contract, but bypass the telephone market, by setting a price such that demand on the market for telephony is zero.

First, consider the case in which firm $T$ chooses to serve both markets. For firm $A$ to accept the contract, we need

$$
L=\left(\frac{\gamma-p_{T}}{2}\right)^{2}-p_{A}^{C}\left(\gamma-p_{A}^{C}-p_{T}\right)
$$

Total profits of firm $T$ equal $^{7} \pi_{T}^{C}=p_{T}\left(1-\alpha p_{T}\right)+p_{T}\left(\gamma-p_{A}^{C}-p_{T}\right)-L$. Using (36), this implies $\pi_{T}^{C}=p_{T}\left(1-\alpha p_{T}\right)+\left(p_{T}+p_{A}^{C}\right)\left(\gamma-p_{A}^{C}-p_{T}\right)-\left(\frac{\gamma-p_{T}}{2}\right)^{2}$. The telephone company maximizes $\pi_{T}^{C}$ subject to the non-negativity constraints on prices. The Lagrangean equals

$$
\mathcal{L}=p_{T}\left(1-\alpha p_{T}\right)+\left(p_{T}+p_{A}^{C}\right)\left(\gamma-p_{A}^{C}-p_{T}\right)-\left(\frac{\gamma-p_{T}}{2}\right)^{2}+\lambda p_{T}+\mu p_{A}^{C},
$$

with $\lambda, \mu$ the respective Lagrange multipliers. Taking first-order conditions

$$
\begin{aligned}
\frac{\partial \mathcal{L}}{\partial p_{A}^{C}} & =\gamma-2\left(p_{A}^{C}+p_{T}\right)+\mu=0 \\
\frac{\partial \mathcal{L}}{\partial p_{T}} & =1+\frac{3}{2} \gamma-2 p_{A}^{C}-\left(\frac{5}{2}+2 \alpha\right) p_{T}+\lambda=0 .
\end{aligned}
$$

The Kuhn-Tucker conditions are given by

$$
\lambda p_{T}=0 ; \quad \mu p_{A}^{C}=0
$$

Solving for $p_{T}$ and $p_{A}^{C}$ yields

$$
\begin{aligned}
p_{T} & =\frac{\gamma-2 \mu+2(1+\lambda)}{1+4 \alpha} \\
p_{A}^{C} & =\frac{5 \mu-\gamma+4 \alpha(\gamma+\mu)-4(1+\lambda)}{2+8 \alpha} .
\end{aligned}
$$

Suppose both $p_{A}^{C}$ and $p_{T}$ are strictly positive. From the Kuhn-Tucker conditions, we then have $\mu=\lambda=0$, thus

$$
\begin{aligned}
p_{T} & =\frac{\gamma+2}{1+4 \alpha} \\
p_{A}^{C} & =\frac{(4 \alpha-1) \gamma-4}{2+8 \alpha}
\end{aligned}
$$

which is feasible if and only if $\alpha>\frac{\gamma+4}{4 \gamma}$. With $\alpha<\frac{\gamma+4}{4 \gamma}$, at least one of the prices has to be zero. Suppose only $p_{T}$ is. Then, using (41) and $\mu=0$, we would have $\lambda=-\frac{1}{2} \gamma-1$,

\footnotetext{
${ }^{7}$ More precisely, $\pi_{T}^{C}=\max \left\{p_{T}\left(1-\alpha p_{T}\right), 0\right\}+\max \left\{p_{T}\left(\gamma-p_{A}^{C}-p_{T}\right), 0\right\}-\max \{L, 0\}$.
} 
which is not feasible. Setting both prices to zero is clearly not profit-maximizing. Thus, necessarily, $p_{A}^{C}=0$. Using $\lambda=0$, equality (42) then yields $\mu=\frac{\gamma(1-4 \alpha)+4}{5+4 \alpha}$, which, from (41), implies

$$
p_{T}=\frac{3 \gamma+2}{5+4 \alpha}
$$

Profits then equal

$$
\pi_{T}^{C}=\frac{(1-\alpha) \gamma^{2}+1+3 \gamma}{5+4 \alpha} .
$$

Note that the condition $\alpha<\frac{\gamma+4}{4 \gamma}$ is always satisfied if $\alpha<\frac{1}{4}$. When $\alpha>\frac{\gamma+4}{4 \gamma}$, we have $p_{A}^{C}$ given by (44). The profits of following this strategy equal

$$
\pi_{T}^{C}=\frac{1}{4} \frac{(2+\gamma)^{2}}{1+4 \alpha}
$$

Alternatively, firm $T$ can choose to bypass the telephone market, but still offer a contract to the ISP. If it does so, we have the exact same analysis as in section 2.4. From (22), profits of following this strategy equal $\gamma^{2} / 5$. Using (47), these profits are higher than the profits of serving both markets and setting $p_{A}^{C}>0$ whenever

$$
\gamma>\frac{4 \sqrt{(5+20 \alpha)}+10}{16 \alpha-1}
$$

Moreover, we then need that $p_{T}$ is such that demand on the telephone market is zero. From (31) and (21), this implies $\gamma \geq \frac{5}{3 \alpha}$. It can be shown, however, that in the relevant interval, where $\alpha>\frac{1}{4}$, condition (48) is sufficient for this to be satisfied.

Now we compare profits of bypassing the telephone market with profits of serving both markets and setting $p_{A}^{C}=0$. Comparing (22) and (46), bypassing the telephone market yields higher profits whenever

$$
\gamma>\frac{1}{6 \alpha}(5+\sqrt{(25+20 \alpha)}) .
$$

Again, we also need $\gamma \geq \frac{5}{3 \alpha}$. Here, (49) is sufficient for that to hold.

Finally consider the possibility of bypassing the market for internet access. Then, from (31), the telephone company maximizes profits by setting $p_{T}=\frac{1}{2 \alpha}$, yielding profits $\pi_{T}=$ $\frac{1}{4 \alpha}$. For this to be more profitable then serving both markets with a contract $p_{A}^{C}=0$, we need, from (46),

$$
\gamma<\frac{3 \alpha-\sqrt{\alpha} \sqrt{(5+4 \alpha)}}{2 \alpha(\alpha-1)}
$$


We then also need that demand on the internet market is nonpositive, thus, from (30), $\gamma \leq \frac{1}{2 \alpha}$, which is always satisfied when (50) is. Finally, the solution is always in the relevant interval where, when serving both markets, the monopolist would set $p_{A}^{C}=0$. It can be shown that bypassing the internet market is never optimal in the relevant interval when the optimal contract has $p_{A}^{C}>0$.

\section{- - - INSERT FIGURE 1 ABOUT HERE - - -}

Figure 1 summarizes the above analysis in $(\alpha, \gamma)$-space. Curve $b$ represents $\alpha=\frac{\gamma+4}{4 \gamma}$. For any points to the left of this curve, the optimal contract when both markets are served, has $p_{A}^{C}=0$. For points to the right of $b$, it has $p_{A}^{C}>0$. On curve $d$, lying to the left of the intersection with $b,(49)$ holds with equality. Thus, to the right of $d$, but to the left of $b$, firm $T$ chooses to bypass the telephone market. On curve $c$, lying to the right of the intersection with $b,(48)$ holds with equality. ${ }^{8}$ Hence, to the right of $c$, firm $T$ also bypasses the telephone market. Finally, on curve $a,(50)$ holds with equality. Thus, below $a$, firm $T$ will bypass the internet market.

Summarizing, we have

Theorem 2 When the telephone market is also taken into account, and the telephone company can offer a contract to the internet service provider, equilibrium prices are given by

$$
\left(p_{T}, p_{A}^{C}, p\right)=\left\{\begin{array}{cc}
\left(\frac{1}{2 \alpha}, \infty, \infty\right) & \text { in area } I \\
\left(\frac{3 \gamma+2}{5+4 \alpha}, 0, \frac{3 \gamma+2}{5+4 \alpha}\right) & \text { in area II } \\
\left(\frac{\gamma+2}{1+4 \alpha}, \frac{(4 \alpha-1) \gamma-4}{2+8 \alpha}, \frac{1}{2} \gamma\right) & \text { in area } I V \\
\left(\frac{3}{5} \gamma, 0, \frac{3}{5} \gamma\right) & \text { in areas III and } V
\end{array}\right.
$$

where the areas refer to figure 1.

Note that offering the contract has two effects for the telephone monopoly. On the one hand, it (partly) solves the double marginalization problem on the market for internet

\footnotetext{
${ }^{8}$ Note that, although it is not possible to see this in the figure, curve $c$ is different from $d$. However, it can be shown that both curves do intersect curve $b$ at the same point.
} 
access. On the other hand, it may decrease profits on the market for regular telephony. In area IV, balancing these two effects implies that firm $T$ does offer a contract, but for some strictly positive access price $p_{A}$. In this area, the full price for internet access always equals $\frac{1}{2} \gamma$, which is the price that maximizes joint profits of firms $T$ and $A$ on the internet market. Thus, the double marginalization problem is fully internalized.

One interesting implication of this analysis is that free internet access may be a temporary phenomenon. For high enough ${ }^{9} \alpha$, as $\gamma$ increases, free internet access (i.e. $p_{A}=0$ ) will initially be offered. Yet, as the internet market increases further, there is a point where firm $T$ changes the terms of the contract offered to the service provider, and induces it to charge $p_{A}=\frac{(4 \alpha-1) \gamma-4}{2+8 \alpha}>0$. As $\gamma$ increases yet further, we shift back to free internet access. But this final shift only occurs when the internet market has grown so large that the market for regular telephony is no longer served.

\subsection{Welfare effects}

For the time being, it seems hard to imagine that internet will make the market for regular telephony obsolete altogether, as is the case in areas III and V. Therefore, our welfare analysis restricts attention to cases in which both markets co-exist. The full price of internet access then always decreases when free internet access is introduced. By solving the double marginalization problem, total deadweight welfare loss on the internet market decreases. This means that both the profits of firm $T$ and consumer welfare can increase. Profits of firm $A$, however, do go down, for the reasons described in section 2.3. In most cases, prices for regular telephony increase, making regular telephone users worse off. Solving the double marginalization problem on the internet access market yields a decrease in $p_{A}$, but often an increase in $p_{T}$, which hurts regular telephone users. The only exception is the area in which $p_{T}=\frac{2+\gamma}{2+4 \alpha}$ with no contract, and $p_{T}=\frac{3 \gamma+2}{5+4 \alpha}$ with a contract, and moreover $\frac{2+\gamma}{2+4 \alpha}<\frac{3 \gamma+2}{5+4 \alpha}$. We thus need $\frac{3 \alpha-\sqrt{\alpha} \sqrt{(5+4 \alpha)}}{2 \alpha(\alpha-1)}<\gamma<\frac{5}{6 \alpha}$ for telephone prices to decrease because of free internet access. In this area, the price that maximizes total profits of firm $T$, is higher than the price that maximizes its profits on the telephone market viewed in isolation. Therefore, firm $T$ can increase profits on the telephone market by lowering its price there, when this does not induce firm $A$ to counterbalance by setting a higher price on the internet market. Under these circumstances, free internet access makes all consumers and the telephone

\footnotetext{
${ }^{9}$ It can be shown that for this, we need $\alpha>0.55$.
} 
company better off. Only firm $A$ is hurt. Total welfare increases.

\subsection{An integrated monopoly}

So far, we have assumed that the telephone company and the internet access provider are two separate monopolists. However, we can also have free internet access when the telephone company fully owns the internet service provider. This can be seen as follows. Again, assume that demand on the internet and telephone market is given by (30) and (31). The Lagrangean of the maximization problem of the monopolist is now given by

$$
\mathcal{L}=\left(p_{A}+p_{T}\right)\left(\gamma-p_{A}-p_{T}\right)+p_{T}\left(1-p_{T}\right)+\lambda p_{T}+\mu p_{A} .
$$

The first order conditions are

$$
\begin{aligned}
& \frac{\partial \mathcal{L}}{\partial p_{A}}=\gamma-2 p_{A}-2 p_{T}+\mu=0 \\
& \frac{\partial \mathcal{L}}{\partial p_{T}}=\gamma-2 p_{A}-2(1+\alpha) p_{T}+1+\lambda=0
\end{aligned}
$$

yielding

$$
\begin{aligned}
& p_{T}=\frac{1}{2 \alpha}(1+\lambda-\mu), \\
& p_{A}=\frac{1}{2}(\gamma+\mu)-\frac{1+\lambda-\mu}{2 \alpha} .
\end{aligned}
$$

A solution with both $p_{T}$ and $p_{A}$ positive implies $\lambda=\mu=0$, thus

$$
\begin{aligned}
p_{T} & =\frac{1}{2 \alpha}, \\
p_{A} & =\frac{1}{2} \gamma-\frac{1}{2 \alpha} .
\end{aligned}
$$

which is only feasible if $\gamma>1 / \alpha$. For $\gamma<1 / \alpha$, with only $p_{T}=0$, we would have $\lambda=-1$, which is not feasible. Thus, in that case, $p_{A}=0$, and $\mu=\frac{1}{2}(1-\gamma)$, hence $p_{T}=\frac{1}{4}(1+\gamma)$. Therefore, the advent of free internet access is not incompatible with a case in which the telephone monopoly fully owns the internet service provider. Yet, also in this case, whether or not free internet access will be offered depends on the size of the internet market compared to that of the telephone market. 


\section{Conclusion}

In this paper, we studied free internet access, the phenomenon observed in several European countries where internet service providers offer their product at zero price. We gave a simple explanation for this phenomenon, by arguing that it is profitable for the telephone monopolist to induce this behavior of ISPs. Specifically, the telephone company has an incentive to offer a contract to the access provider, promising to pay him a certain lumpsum amount, when the provider offers free, or substantially cheaper, internet access. By offering such a contract, the telephone company solves a double marginalization problem.

In a simple set-up, where we only consider the market for internet access, we showed that, among all contracts the telephone company may offer, the one that implies free internet access is indeed the one that maximizes its profits. When there are some fixed costs to contracting, free internet access will only emerge when the market has reached some critical size. When the market for internet access is an oligopoly, that critical size is increasing in the number of oligopolists.

We also studied the incentives of offering free internet access when the market for regular telephony is also taken into account. In that case, the telephone monopoly may choose to offer a contract that induces the internet service provider to set some positive price. Free internet access will be offered when the internet market has reached some critical size, yet a strictly positive price for internet access will be reintroduced when the market grows larger. The intuition for this result is that, when free internet access is offered, the telephone firm captures additional profits on the internet market by increasing the price of regular telephony. Yet, those profits may be outweighed by the losses this price increase

induces on the regular telephone market. If that is the case, the telephone monopoly will still offer a contract to the internet service provider, yet this contract will now specify some positive price for internet access. As the market for internet access grows even larger, we switch back to free internet access. By then, the regular telephone market is no longer served.

When we assume that the markets for internet access and regular telephony will continue to co-exist, we obtain the following welfare effects. Internet users are always better off when free internet access is offered. Regular telephone users are only better off when the market for internet access is still relatively small. When the size of that market increases, they are worse off. Trivially, the telephone monopoly is always better off. The 
internet service monopoly however, is worse off. It is free to decline the contract the telephone monopoly offers, yet this contract is designed in such a way that it also makes the outside option for the service monopolist less attractive than it was in the case without a contract. Finally, we showed that when the telephone monopoly fully owns the internet service provider, offering free internet access can also be a profit-maximizing strategy for the monopolist.

We assumed that the market for telephony is a monopoly. The results of this paper may change profoundly if this is no longer the case. Indeed, in the Us, where the market for telecommunications is more competitive, free internet access is not being offered the way it is offered in Europe. That is peculiar, since the market for internet access in the US is arguably the largest in the world. In the framework of our paper, however, this does not come as a surprise. In the Us, the price for local telephone calls often equals zero. Therefore, there is no double marginalization problem, and telephone companies are not willing to pay a lump-sum to ISPs, conditional on them offering free internet access. Hence, free internet access is not observed in the US. Also, the results of this paper may change if internet access can be offered in different ways, for example via cable. Finally, we assumed that the telephone monopoly is able to set the price it chooses. With regulated prices, free internet access is less likely to occur. Yet, also in this case, it is easy to show that free internet access can be the optimal strategy for the telephone monopoly.

From the analyses in this paper, there seems little reason for antitrust authorities to worry when free internet access is introduced. Total welfare increases, as the double marginalization problem is solved. This increase in welfare may entail some redistribution from telephone users and internet service providers towards internet users and the telephone company. Antitrust authorities may have reason to worry if the telephone company also starts to offer internet access. If it does, the telephone company may simply drop the contracts it offered to the incumbent ISPs, and offer free internet access only through its own ISP. Since in such a scenario the original ISPs will hardly be able to make profits, they will drop out of the market, leaving the telephone company with a monopoly on both the market for regular telephony and internet access. 


\section{References}

Kreps, D. M., and J. A. Scheinkman (1983): "Quantity Precommitment and Bertrand Competition Yield Cournot Outcomes," Bell Journal of Economics, 14(2), 326-37.

Singh, N., and X. Vives (1984): "Price and Quantity Competition in a Differentiated Duopoly," Rand Journal of Economics, 15(4), 546-54.

Spengler, J. (1950): "Vertical Integration and Anti-trust Policy," Journal of Political Economy, 58, 347-52.

TelegraAF (1999): "ING Groep gaat iedereen gratis internet leveren," August 31.

The Economist (1999a): "Dixons comet," July 31.

— (1999b): "Trawling for surfers," May 1.

Tirole, J. (1988): The Theory of Industrial Organization. Mit-Press, Cambridge, Mass.

VAN Jole, F. (1999): "Het grote landjepik op een gratis internet," Volkskrant, september 11.

VolKSKRant (1999): "De tijd is rijp voor de weggeefeconomie," August 25.

YuRKo, C. (1994): "Users pour into free ISPs," http://cnn.com/TECH/computing/9910/13/free.isp.int.idg. 


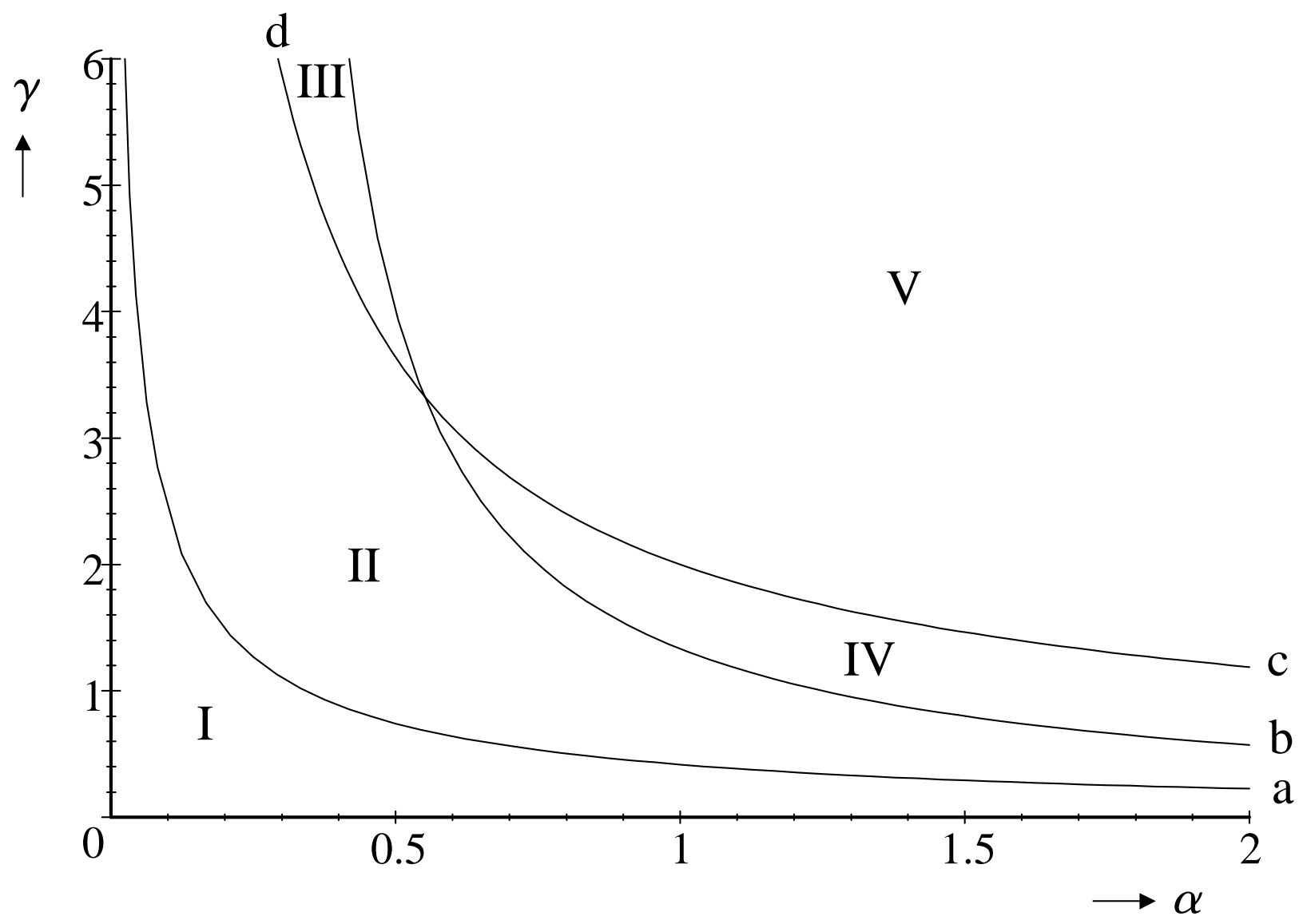

Figure 1. Free internet access with two markets 